$\star$ 一一論文

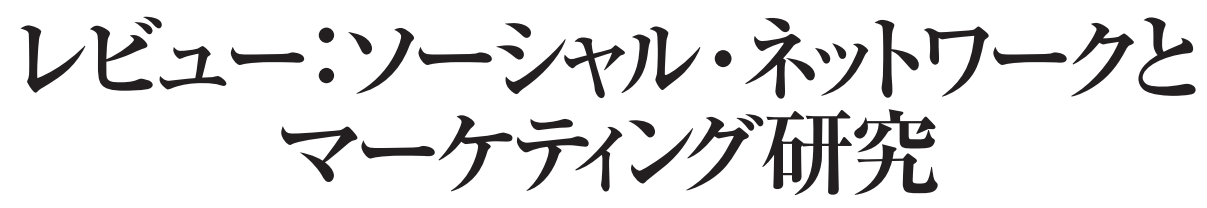

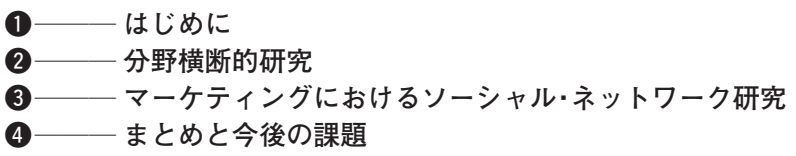

\section{大西 浩志}

ミシガン大学 ロス・スクール・オブ・ビジネス

1 はじめに

近年，ソーシャル・ネットワークをマーケ ティングに活用する事例が，注目を集めてい る。マーケティング実務においては，2005年 にNews 社が，若者向け米国のソーシャル・ ネットワーク・サイトの大手 MySpace を 5 億 8,000 万ドルで買収している。また, Microsoft 社は，2007 年，Facebook に 2 億 4000 万ドル を出資して同社株式の $1.6 \%$ を取得し，さら に買収の準備を進めていると報道されている ${ }^{1)} 。$ Nielsen Online によると, 2007 年末の段階で, Facebook と MySpaceには，それぞれ約 1 億 人，LinkedIn には，2 千万人の登録者がいる と報告されている。一方，マーケティング研 究においては，2008年 6 月に開催された INFORMS のマーケティング・サイエンス学 会で，ソーシャル・ネットワークの特別セッ ションが連続 6 回設定され, 関連する研究が 27 本報告された。

本稿では，これらの動向を踏まえて，特に 近年のマーケティング研究における, ソーシ ヤル・ネットワークを扱った論文を概観する。
ただし，ここでのソーシャル・ネットワーク は, MySpaceのようなオンライン・コミュニ ティに限定せず，医師が新薬の情報を共有す るネットワークのような，特定目的の職業 的・専門的ネットワークや，携帯電話で通話 する仲間などの通信ネットワークも含む。つ まり，個々の人間が，何らかの方法によって， 相互に情報伝達可能なネットワーク構造を持 つとき，それらをソーシャル・ネットワーク として扱う。また，実際にデー夕を分析した 実証研究論文を主に紹介し, 理論研究や実験 デー夕を用いた論文については，本稿では詳 述しない。

\section{2 分野横断的研究}

ソーシャル・ネットワーク研究の一つの特 徵は, 分野横断的ということである。研究分 野は，社会学，応用数学，経済学など多岐に 渡っている。後述するマーケティングにおけ るソーシャル・ネットワーク研究でも，これ らの先行研究の成果を取り入れた研究が行わ れている。

社会学では, 主に, ネットワークの構造に 関する研究が行われている。古くは，疫病の 伝播ネットワーク研究 (Coleman, Katz and 
Menzel 1966; Schelling 1971; Granovetter 1973, 1978; Burt 1987)，オピニオン・リーダ 一や社会的地位の研究 (Bothner, Kim and Lee 2006; Watts and Dodds 2007) などがあ る。

応用数学（ネットワーク理論）では，スモ ール・ワールド現象（世界中の誰とも平均 6 人 を仲介すれば繋がる）の理論モデル研究 (Watts and Strogatz 1998) やネットワーク の連結数の闇值を数值計算するカスケード • モデル (Dodds and Watts 2004; 2005) など がある。

\section{3) マーケティングにおけるソー シャル・ネットワーク研究}

インターネット上でのソーシャル・ネットワ ーク・サイトの流行によって, メンバーの行 動デー夕が, 大量に容易に入手できるように なったことで，近年，マーケティングにおけ るソーシャル・ネットワーク研究が, 数多く行 われるようになっている。

ソーシャル・ネットワーク研究で用いられて いる統計モデルには，大きく分けて，受動的 相互作用 (passive interaction) モデルと能動 的相互作用 (active interaction) モデルがあ る。受動的相互作用モデルでは, エージェン トの状態変化は, ネットワークの他のエージ ヨントの行動ではなく, 状態のみによって外 性的に影響を受ける。受動的相互作用モデル の例として，バス・モデル（Bass 1969）のよ うな普及モデルでは，エージェントが製品を 採用する確率が, 既に製品を採用している他 のエージェントの数による関数になっている。 すなわち, 個々のエージョントの行動ではな
く, 全体のシェア (採用数) のみが, 他のエ ージェントに影響を及ぼしている。

歴史的には, 受動的相互作用モデルが能動 的相互作用モデルに先行する。しかし, 近年 のソーシャル・ネットワーク研究で用いられて いるモデルの多くは, 能動的相互作用モデル である。以下では, 受動的相互作用モデルを 用いた研究 (ソーシャル・ネットワーク研究に 限定しない）について概観し，次に，能動的 相互作用モデルの研究を詳しく紹介する。ま た，能動的相互作用モデルをデー夕に適用す る際に問題となる, 識別問題についても解説 する。

\section{1. 受動的相互作用モデル}

受動的相互作用モデルの定義は, エージェ ントの行動が, 少なくとも以下の条件の一つ を満たしていることである。（1）個々エージ エントの行動が, 他のエージェントの状態を 変化させない。普及モデルの例では, 他の工 ージェントの採用数（シェア）を変化させな い。（2）個々エージェントの行動が, 他のエ ージェントの採用行動を変化させない。 個々エージェントの行動が, 他のエージェン トの状態の選択確率を変化させない。

受動的相互作用モデルの代表例として，（疫 学的）疾病伝播モデル, 製品普及モデル, 空 間モデルがある。疾病伝播モデルは, 集団の 中で病気が伝播する速度を予測することを目 的としている (e.g., Durett 1999; Van den Blute and Wuyts 2007)。典型的な疾病伝播モ デルは, エージェントの状態を, 感染前 (Susceptible), 感染 (Infected), 治癒 (Recovered）に分類し，エージェントは，そ れらの状態をランダムに移動すると仮定する。 
したがって，これらのエージェントは受動的 である。なぜなら，エージェントの状態は， 集団の状態のみに依存し，他のエージェント の行動自体には影響されないからである。製 品普及モデルは，これらの疾病伝播モデルを マーケティングに応用したものである。例と して，上述したバス・モデルでは，他のエー ジェントのシェア (採用数) が, 線形にエー ジェントの製品採用確率に影響する。バス・モ デルは, $\mathrm{S}$ 字型の普及曲線であり, 典型的な 集計済みデータに対して，良く適合する。し かしながら，個人の異質性や，未観測の時変 変数の影響を考慮しておらず，推定結果には 集計バイアスが内在することが指摘されてい る(Glaeser, Sacerdote and Scheinkman 2003)。 最後に, 空間モデルは, 距離, もしくは属性 の近いエージェント間の相関構造を推定する ことを目的としている (e.g., Yang and Allenby 2003)。これらのモデルも, エージェント 個人の行動は，互いに影響を与え無いことか ら，受動的相互作用モデルである。

\section{2. 識別問題}

能動的相互作用モデルを詳述する前に, 実 験以外の方法で，データからネットワーク・ モデルを用いて推定を行う場合に，注意が必 要だと指摘されている 3 つの識別問題につい て説明する。これらの識別問題は, エージェ ント間の行動の因果の方向を推定するために 生じる問題である。なぜなら，限られたデー 夕からは，見せ掛けの因果関係と，ネットワ ークによる因果関係を識別することは不可能 だからである。（受動的相互作用モデルは，エ ージェントの行動ではなく, 状態の相関関係 を対象としているため，この識別問題は生じ
ない。)

（1）内生的グループ構築問題（Endogenous group formation）は，例えば，エージェント の嗜好の類似性によって, 異なるネットワー クに属するエージェントが，見掛けの上で同 一の行動を取ってしまうことである。したが って，分析者は，エージェントが同一の行動 を取っているからといって，それらのエージ エントを同一のネットワーク・グループに分 類することはできない。例えば，グループの 定義は，距離的親近性などを基に，外性的に 与えられなければいけない。例えば，Nair， Manchanda and Bhatia (2006) は，医師のネ ットワークを，実際に，医師に調査したネッ トワーク・データを用いて外性的に定義して いる。また, Hartman and Yildiz (2006) で は，ゴルフ仲間のネットワークを，同じ時間 帯にクレジットカードを使用したペアをパー トナー・ネットワークと定義している。

（2）未観測の相関変数 (Correlated unobservables), 特に, 未知の時変変数の影響も, 識別問題の原因となる。ネットワークは，動 的に構築されるため, 未知の時変変数の影響 とネットワーク構築の影響を分離することが, 困難であるからである。デー夕が入手可能で あれば, 適切な操作変数を導入することによ って, 問題を解決することができる。また, 固定効果変数や, difference-in-difference モ デルを用いることによって，ある程度，問題 を緩和することが可能であるが，未知の時変 変数の影響を，完全に排除することはできな (2)。

（3）同時性問題 (Simultaneity) は, エージ エントの意思決定と他のエージェントの意思 決定のどちらが，先に原因となったか特定で 
きないことにより生じる。また，あるエージ エントの行動が, 他のエージェントの行動に 影響し，同時に，他のエージェントの行動が 逆に影響を与えることもあり，この問題は “reflection problem”とも呼ばれる（Manski 1993)。操作変数を用いることで，この問題を 解決できる (Manchanda, Xie and Youn 2007)。 しかしながら, 操作変数の選択基準として, あるエージェントの意思決定のみに影響し， 他のエージェントの行動には関与しないこと が必要であり, 適切な操作変数を見つけるこ とは，しばしば困難である。他の方法として， 均衡条件をモデルに組み込むことにより, 同 時性問題を解決することもできる（Hartman and Yildiz 2006)。

データを用いてエージェントの行動の因果 関係を分析する際，上記の識別問題は避ける ことができない。これらの問題を解決するた めには，付随するデー夕が豊富であることが 必要である。内生的グループ構築問題を解決 する一つの方法は, 外性的にグループの定義 を与えることであるが，そのグループはエー ジェントの行動データからではなく，それ以 外のデー夕から定義されなければならない。 一方, 操作変数を用いる場合も, 適切な操作 変数は, エージェントの行動デー夕と強く相 関してはならない。例えば, Manchanda, Xie and Youn (2007) は，同時性問題を解決する ために，一時点前の医師グループの新薬採用 確率を，操作変数として導入している。一時 点前の個別の医師の行動は, その後の行動に 強く相関するが，現時点の医師グループの行 動とは弱い相関しかないため, 操作変数選択 の基準を満たしている。適切な操作変数を見
つけることは，しばしば困難であるが，識別 問題を解決するために有効な手段である。

\section{3. 能動的相互作用モデル}

近年のソーシャル・ネットワーク研究で用い られているモデルの多くは，能動的相互作用 モデルである。上述の定義の通り, 能動的相 互作用モデルは，エージェントの状態よりも， その行動に着目しているため, 全体の状態 （シェア）よりも，詳細な個人レベルでの分析 が可能となる。以下，能動的相互作用モデル を用いた研究を，(1）ネットワーク発生・発 展の研究，(2）オピニオン・リーダーの役割 の研究, (3) ネットワーク内普及の研究に分 類して解説する。

（1）ネットワーク発生・発展の研究 近年のマーケティングにおけるソーシャ ル・ネットワーク研究で, 最も多く取り上げ られているのが，ネットワークの発生，およ び発展の研究である。これらの研究では, 動 的なネットワークの発展が, どのような要因 によって影響を受けるのか，また，その発展 の経路が研究対象である。

ネットワーク発展の要因として, ネットワ ークの構造，二者間の関係，エージェントの 属性（性別，年齢）などが挙げられている。 ネットワーク構造を要約する指標は, 過去の 研究で数多く提案されている。社会学などの ネットワーク分析で用いられる, リンクの平 均数 (degree effect) とリンクの密度 (clustering effect）が, マーケティング研究におい ても使われ，ネットワーク発展の要因と確認 されている (Katona, Zubcsek and Sarvary 2007）。また，ネットワーク構造の指標として, 
嘹好などを同じくする仲間（homophily）の 影響も指摘されている。仲間は，潜在変数に よる親近度（Narayan and Yang 2007），外性 的に定義した友人関係（Trusov, Bodapati and Bucklin 2006）などによって定義されて いる。二者間の関係は，ネットワーク全体の 構造ではなく, 特定の二者間のエージェント の関係に着目した指標である。Narayan and Yang（2007）によると，二者間の関係は，因 果関係の無い相互関係 (reciprocity), 方向性 を持った関係 (duality)，そして嗜好などを 同じくする仲間 (homophily) に分類される。

ネットワーク発展の経路は, 動学的モデル を用いて, 理論面と実証面で研究されている。 実証的研究としては, 個別エージェントのネ ットワークヘの参加確率を普及モデル（微分 方程式）で推定するもの（Katona et al. 2007） やエージェント間のリンクが構築されるタイ ミング（経過時間）をハザード・モデルで推定 するもの（Narayan and Yang 2007）がある。

（2）オピニオン・リーダーの役割の研究 オピニオン・リーダーを特定し，その影響 力を知ることは, マーケティング, 特に実務 において重要である。オピニオン・リーダー は, 口コミの起点であり, 彼らの行動の影響 は，ネットワークの中を伝播する間に，雪だ るま式に増大する。例えば, マーケターは, オピニオン・リーダーのみに接触することで, ネットワーク全体に接触するよりも効率的に 対話することができる。また，ネットワーク 研究では, このように一人のエージェントか らネットワーク全体に対して，影響が連鎖に よって増大することを, 社会的乗数 (Social multiplier) と呼ぶ。
前述の通り, 内生的グループ構築問題によ る識別問題のため, 実証分析では, 外性的に オピニオン・リーダーを定義する必要がある。 例えば，直接調査によりオピニオン・リーダー を特定する（Nair et al. 2006）, 他のエージェ ントからの信頼度を代理変数にする (Narayan and Yang 2007), 実際に影響を受 けた他のエージェント数を事後的にカウント する（Katona et al. 2007）などの定義が用い られている。それらの実証研究では, オピニ オン・リーダーのネットワークへの影響が示 唆されている。Nair et al. (2006) は，医師間 ネットワークにおける処方回数について, 調 査で特定したオピニオン・リーダーによる社会 的乗数を推定している。

\section{（3）ネットワーク内普及の研究}

ネットワーク内普及とネットワークの普及 は，区別される。ネットワークの普及は，ネ ットワークの発展であり，エージェントがネ ットワークに参加する行動である。一方，ネ ットワーク内の普及には, 情報の普及（口コ ミ）と製品・サービスの普及がある。

ネットワーク内の口コミ研究は, 従来の口 コミ研究を, ネットワーク, 特にオンライ ン・ネットワークに発展させたもので, 数多 く存在する。口コミを評価する指標として, ロコミの量, 分散, 好意度 (ポジティブ / ネ ガティブ）が，対象となる商品・サービスの 評価や売上と相関しており，売上予測などに おいて重要な指標となっている（Godes and Mayzlin 2004 ; Liu 2006 など)。

ネットワーク内での製品・サービスの普及 は, 現時点で研究が進んでいない分野である。 その主要因は, 研究者が利用可能な製品・サ 
ービスの普及データが整備されていないため である。数少ない実証研究として，医師間ネ ットワーク内の新薬普及 (Manchanda et al. 2007）や通信ネットワーク内での新サービス の普及（Hill, Provost and Volinsky 2006）な どがある。

受動的相互作用モデルと能動的相互作用モ デルの区分は，それらの応用での，マーケテ イング戦略決定に大きな違いをもたらす。受 動的相互作用モデルは, 社会的乗数 (ネット ワークによる連鎖効果）の影響をより強く推 定するため，初期のわずかなマーケティング 政策の違いでも，大きな結果の相違をもたら すことになる。さらに，受動的相互作用モデ ルは，同時性問題などの識別問題を含むため， その推定結果などの解釈には注意が必要であ る。

\section{4-まとめと今後の課題}

近年のソーシャル・ネットワーク・サイト の隆盛は，ビジネスとして，また，マーケテ イングの研究対象として注目を集めている。 また，オンラインのデータが容易に大量に入 手できるようになったことで, マーケティン グの実証研究が数多く行われるようになって きている。本稿では, それらの実証研究論文 を中心に，近年のソーシャル・ネットワーク を扱ったマーケティング研究を紹介した。

それらの研究では, 能動的相互作用モデル を使ってデー夕分析している。能動的相互作 用モデルは，エージェントの状態よりも，そ の行動に着目しているため, 全体の状態（シ エア）よりも，詳細な個人レベルでの分析が
可能となる。本稿では, 既存研究を, ネット ワーク発生・発展の研究, オピニオン・リー ダーの役割の研究, ネットワーク内普及の研 究に三分類して紹介した。しかしながら，動 的なネットワークの発展要因, およびその発 展経路の研究は盛んであるが, 本来のマーケ ティング研究の課題である, 製品・サービス のネットワーク内での普及は，まだわずかな 研究しか行われていない。利用可能なアウト プット・データが整備されていないことが, 主な原因であるが, さらなる研究事例が必要 である。さらに，実デー夕を用いた能動的相 互作用モデルには, 識別問題が存在するため, 分析段階での操作変数の選択や, 結果の解釈 において注意が必要である。

最後に, ソーシャル・ネットワーク研究の 最大の特徵は, 分野横断的に研究が行われて いる点である。社会学, 応用数学, 経済学で は，マーケティングに先行して研究が行われ ており, 多くの知見が蓄積されている。今後 のマーケティング研究では, 他の分野と共同 し, さらにマーケティング独自の視点を追加 した研究が必要になると考えられる。

\section{注}

1) The New York Times, "At Social Site, Only the Businesslike Need Apply," June 18, 2008。

2) 操作変数法, 固定効果変数, difference-in-difference モデルについては, 計量経済学のテキスト, G.S. Maddala 著（佐伯訳）「計量経済分析の方法」, W. H. Greene著（斯波, 中妻, 浅井訳)「経済学体 系シリーズ：グリーン計量経済分析 I/II」などを参 照。

\section{参考文献}

Bass, F. M.(1969), “A new product growth model for consumer durables”, Management Science, 15, pp. 215227.

Bothner, M. S., Y. K. Kim and W. Lee(2006), “Primary 
Status, Complementary Status, and Capital Acquisition in the U.S. Venture Capital Industry," Working Paper, University of Chicago.

Burt, R. S.(1987), “Social Contagion and Innovation: Cohesion versus Structural Equivalence, “American Journal of Sociology, 92(May), pp. 1287-1335.

Coleman, J. S., E. Katz and H. Menzel(1966), Medical Innovation, New York: Bobbs-Merrill.

Dodds, P. S. and D. J. Watts(2004), “Universal Behavior in a Generalized Model of Contagion,” Phys. Rev. Lett., Vol. 92, article 218701.

Dodds, P. S. and D. J. Watts(2005), “A Generalized Model of Social and Biological Contagion," Journal of Theoretical Biology, Vol. 232, pp. 587-604.

Durrett, R.(1999), “Stochastic Spatial Models,” SIAM Review, 41, 4, pp. 677-718.

Glaeser, E. L., B. I. Sacerdote and J. A. Scheinkman(2003), "The Social Multiplier," Journal of the European Economic Association, 1(April-May), pp. 345-353.

Godes, D. and D. Mayzlin(2004), "Using Online Conversations to Study Word-of-Mouth Communication," Marketing Science, 23(4), pp. 545-560.

Granovetter, M.(1973), “The Strength of Weak Ties," American Journal of Sociology, 78(May), pp. 13601380 .

(1978). “Threshold Models of Collective Behavior," American Journal of Sociology, Vol. 83, No. 6, pp. 1420-1443.

Hartmann, W. R. and V. T. Yildiz(2007), “A Structural Analysis of Joint Decision-Making,” Working Paper, Stanford University.

Hill, S., F. Provost and C. Volinsky(2006), “NetworkBased Marketing: Identifying Likely Adopters via Consumer Networks," Statistical Science, Vol. 21, No. 2, pp. 256-276.

Hoff, P. D., E. Raftery, and M. S. Handcock(2002), “Latent Space Approaches to Social Network Analysis," Journal of the American Statistical Association, Vol. 97, No. 460, pp. 1090-98.

Katona, Z., P. P. Zubcsek and M. Sarvary(2007), “Joining the Network: Personal Influences as Determinants of Diffusion,” Working Paper, INSEAD.

Liu, Y.(2006), “ Word of Mouth for Movies: Its Dynamics and Impact on Box Office Revenue," Journal of Marketing, 70(July), pp. 74-89.

Manchanda, P., Y. Xie and N. Youn(2007), “The Role of Targeted Communication and Contagion in Product Adoption," Marketing Science, forthcoming.
Manski, C. F.(1993), “Identification of Endogenous Social Effects: The Reflection Problem," Review of Economic Studies 60, pp. 531-542.

Narayan, V. and S. Yang(2007), “Modeling the Formation of Dyadic Relationships Between Consumers in Online Communities," Working paper, NYU.

Nair, H., P. Manchanda, and T. Bhatia(2006), “ Asymmetric Peer Effects in Physician Prescription Behavior: The Role of Opinion Leaders," Working Paper, Stanford University, Available at SSRN: http://ssrn.com/abstract=937021.

Nam, S., P. Manchanda, and P. K. Chintagunta(2007), “The Effects of Service Quality and Word of Mouth on Customer Acquisition, Retention and Usage, “ Working paper, University of Chicago.

Schelling, T.(1971). "Dynamic Models of Segregation," Journal of Mathematical Sociology, 1, pp. 143-186.

Trusov, M., A. V. Bodapati and R. E. Bucklin(2006), "Your Members are Also Your Customers: Marketing for Internet Social Networks," Working paper, University of Maryland.

Van Den Bulte, C. and S. Wuyts(2007), Social Networks and Marketing, Marketing Science Institute, Cambridge, MA.

Watts, D. J. and P. S. Dodds,(2007), “Influentials, Networks, and Public Opinion Formation,” Journal of Consumer Research., Vol. 34(December), pp. 441-458.

Watts, D. J. and S. H. Strogatz(1998), “Collective dynamics of † small-world I networks," Nature 393, pp. 440-442.

Yang, S., and G. Allenby(2003), “Modeling Interdependent Consumer Preferences," Journal of Marketing Research, Vol. XL(August 2003), pp. 282-294.

大西浩志（おおにしひろし）

1996 年大阪大学経済学部卒業，1998 年同大大学院 経済学研究科経営学専攻博士前期課程修了。1998 年 -2005 年株式会社ビデオリサーチ。 2005 年より, ミシガン大学ロス・スクール・オブ・ビジネス 博 士課程マーケティング専攻在学。 